\title{
TERMODINÂMICA APLICADA A PROCESSOS CLIMÁTICOS
}

\author{
Eliana Suzy Wakassugui dos Santos², Ritchielli Cristine Schröder ${ }^{3}$, Carlos H. Coimbra-Araújo ${ }^{4}$
}

\author{
${ }^{1}$ Aceito para publicação, $2^{\circ}$ trimestre de 2013. \\ ${ }^{2}$ Graduanda em Tecnologia em Biocombustíveis, Monitora da disciplina Termodinâmica (bolsista), Setor \\ Palotina, Universidade Federal do Paraná \\ ${ }^{3}$ Graduanda em Tecnologia em Biotecnologia, Aluna de Iniciação Científica (voluntária), Setor Palotina, \\ Universidade Federal do Paraná \\ ${ }^{4}$ Doutor em Ciências, Mestre em Ciências, Engenheiro Eletrônico, Professor Adjunto 2, Setor Palotina, \\ Universidade Federal do Paraná
}

Palavras-chave: Termodinâmica, Ciclo de Carnot, Climatologia, Entropia.

\section{Resumo}

A termodinâmica tem uma gama muito ampla de aplicações, uma vez que é utilizada em uma grande variedade de disciplinas científicas e processos tecnológicos. Este trabalho concentra-se em ciências do ambiente e estudo de exemplos de como um modelo simples de motor de Carnot e uma teoria da produção de entropia pode esclarecer sobre o sistema climático da Terra e como conseqüência a compreensão das mudanças climáticas por fatores antropogênicos e outras influências. Este modelo é verificado, também, para o caso das tecnologias ambientais como processos de energias renováveis. Baseado nos cálculos da Eficiência de Carnot, para aspectos climáticos, utilizou-se a temperatura média do Equador e foram coletadas temperaturas médias máximas de cem cidades, do hemisfério sul, durante o verão e inverno e, cem cidades do hemisfério norte também no período de verão e inverno, sendo que em ambas deduziu-se um conjunto de eficiências de Carnot. Os resultados estão dispostos em tabelas e em alguns gráficos, onde são associadas as latitudes com os resultados dos cálculos da eficiência de Carnot para cada cidade. Como conclusão do trabalho, pode-se dizer que, nos hemisférios tanto norte quanto sul, no inverno há maior eficiência de Carnot do que no verão. Localidades afastadas do Equador apresentam uma maior eficiência de Carnot, devido ao trabalho termodinâmico que, para distribuir calor, torna-se maior, ou seja, a transferência de calor neste espaço é maior se comparado a cidades localizadas no trópico do 
Equador. Assimetrias entre os invernos do hemisfério norte e sul são observadas, o que demonstra que possivelmente o grau de industrialização, bem como a disposição das cidades no hemisfério norte criam uma curva menos acentuada que aquela do hemisfério sul.

\section{Introdução}

A termodinâmica tem uma gama muito ampla de aplicações, uma vez que é usada em uma grande variedade de disciplinas científicas e processos tecnológicos. Sendo o elemento essencial do desenvolvimento de diversas ciências aplicadas e áreas de conhecimento tecnológico, a Termodinâmica abrange aplicações variadas como a oceanografia, a geologia e ciências ambientais, dentre as quais meteorologia, climatologia e ecologia, sendo também o elemento essencial da formulação de modelos descritivos, explicativos e preditivos de fenômenos natural tais como o comportamento da atmosfera, dos oceanos e outros fenômenos relacionados ao clima. (FIGUEIRO, 2008)

A segunda lei da termodinâmica, do ponto de vista macroscópico, pode ser entendida como uma lei de evolução no sentido de definir a seta do tempo. Que define processos reversíveis que ocorrem em constante equilíbrio e processos irreversíveis onde a energia útil perdida no processo nos leva a um sistema que evolui de maneira degradativa. No processo irreversível após o sistema ter caminhado por um caminho o mesmo não pode retornar ao ponto de inicio sem provocar mudanças na vizinhança assim sendo necessário empregar trabalho ao sistema. O enunciado de Kelvin nos diz que: não há nenhum processo no qual calor é extraído de uma fonte e convertido inteiramente em trabalho útil, sem nenhuma outra conseqüência para o resto do universo.

O termo "sem nenhuma outra consequência" indica que o processo deve voltar ao estado original, ou seja, o processo deve ser reversível e portanto denomina-se processos cíclicos e a formulação de Kelvin poderia ser enunciada de outra forma: não há nenhuma máquina térmica operando ciclicamente capaz de retirar calor de um reservatório e convertê-lo integralmente em trabalho. Desse enunciado segue o seguinte teorema de Carnot: nenhuma máquina térmica que opere entre duas fontes diferentes de calor pode ter rendimento superior ao de uma máquina de Carnot. Sendo assim tal máquina é utilizada como comparação em máquinas reais para calcular suas eficiências.

A Climatologia tem o seu estudo voltado à espacialização dos elementos e fenômenos atmosféricos e de sua evolução. Constituindo o estudo científico do clima, a Climatologia trata dos padrões de comportamento atmosférico em suas interações com as 
atividades antropogênicas e com a superfície do Planeta durante um longo período de tempo [4] [5]. De acordo com Mendonça e Danni-Oliveira (2007, p. 15) [2], os elementos que constituem o clima são a temperatura, a umidade e a pressão atmosférica que, em suas diferentes manifestações, variam espacial e temporalmente em decorrência da influência da latitude, altitude, maritimidade, continentalidade, vegetação e atividades humanas, que são fatores geográficos do clima. Sendo um dos constituintes do clima, a latitude influência principalmente na temperatura de um local, estando inversamente proporcional a esta, já que quanto maior a latitude menor a temperatura, pois a variação de redução ocorre sempre quando se desloca do Equador em direção aos pólos.

Este trabalho concentra-se em ciências do ambiente e estudo de exemplos de como um modelo simples de motor de Carnot e uma teoria da produção de entropia pode lançar alguma luz sobre o sistema climático para uma abordagem como a Terra e a consequente compreensão das mudanças climáticas por fatores antropogênicos e outras influências. O presente trabalho tem por objetivo calcular a eficiência de Carnot, a partir de latitudes de duzentas cidades do globo terrestre, utilizando as temperaturas médias máximas durante o inverno e o verão, assim também associada às temperaturas médias máximas da linha do Equador, onde os resultados facilmente nos levam a compreender que a Terra pode ser considerada uma grande máquina térmica, cujo fluxo de calor ocorre partindo do Equador para as maiores latitudes, em um sistema de produção de entropia. O trabalho gerado no processo induz aos diversos climas e fenômenos de circulação conhecidos no planeta Terra.

\section{REVISÃO BIBLIOGRÁFICA}

No globo terrestre nota-se que a radiação solar possui uma maior incidência entre os trópicos, como mostra a figura 1, possuindo uma maior incidência hora no hemisfério norte no trópico de câncer, denominando a estação do verão e, portanto estação de inverno ao sul do planeta, ao contrario também é verdadeiro quando os raios solares incidem com maior frequiência no hemisfério sul, no tropico de capricórnio, denominando a estação de verão e consequentemente inverno no hemisfério norte, isso devido à inclinação da Terra somado ao movimento de translação, fazendo com que um dos hemisférios receba mais radiação solar do que o outro hemisfério em determinadas épocas do ano. 


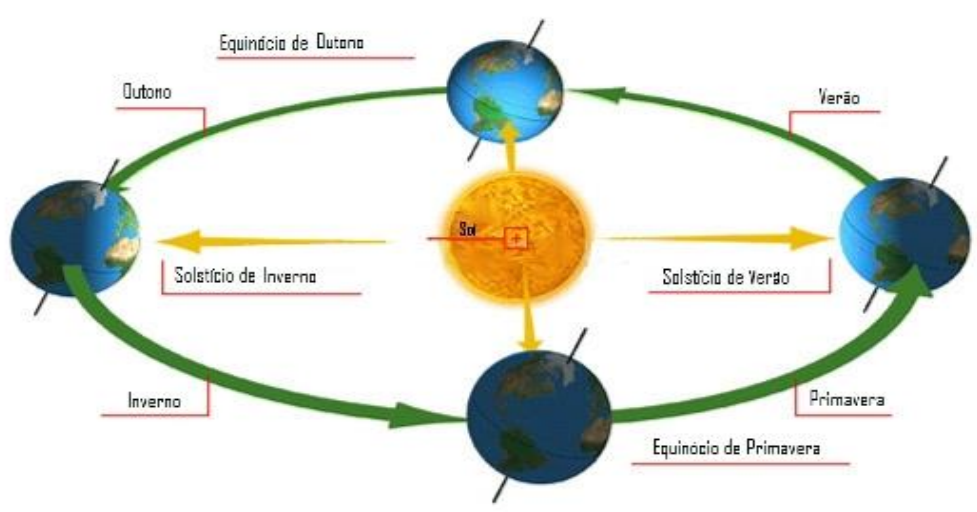

Figura 1: Estações do ano

Outro fator importante se da pela diferença de temperatura e pressão da Terra que para levar a uma distribuição de calor dos trópicos aos pólos é necessário os ventos, originando-se da diferença de temperatura que ocorre no globo, promovendo um aquecimento nos trópicos, o ar torna-se mais leve e sua entropia maior,assim ao chegar aos pólos os ventos sofrem um resfriamento, onde o ar resfria-se e torna-se mais denso com uma entropia menor, com esta diferença de pressão e entropia os ventos se deslocam no globo indo do Equador para os pólos e vice-versa com isso dando origem às correntes de ventos. Segundo Geomundo [7], para o movimento cíclico das correntes de ventos isso se deve ao Efeito de Coriolis, tratasse da tendência que qualquer corpo ou fluido em movimento mudar seu curso devido à direção rotacional e da velocidade da Terra.
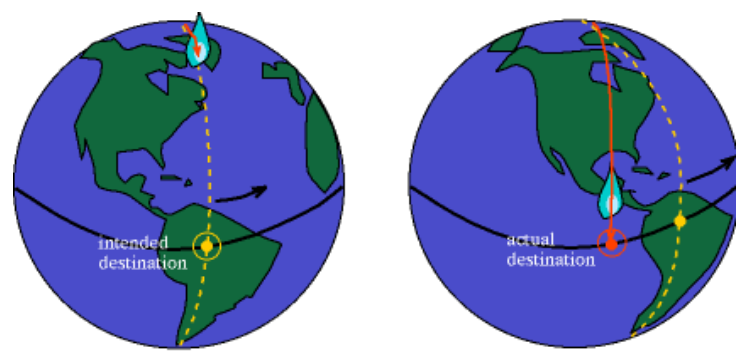

Figura 2: Efeito Coriolis

As máquinas térmicas reversíveis têm a finalidade de gerar trabalho mecânico a partir de pelo menos duas fontes de calor em temperaturas diferentes, estabelecendo um ciclo de operação, sendo que a máquina térmica ideal é a de Carnot por esta maximizar ganhos, já que o trabalho pode ser extraído sem alterar a entropia do universo (OLIVEIRA, 2003)[4]. 
Carnot (1824) concluiu que o melhor aproveitamento dependia apenas das temperaturas das fontes quente e fria operando em um ciclo, assim também denominado ciclo de Carnot.

O ciclo de Carnot é um ciclo idealizado, reversível, no qual o fluido operante é um gás perfeito, que corresponde a duas transformações isotérmicas e duas adiabáticas, intercaladas. Tal ciclo nos proporciona teoricamente qual seria a maior porcentagem em eficiência de uma máquina térmica real.

\section{Material e Métodos}

Tendo em vista que a termodinâmica é a ciência que trata de calor, trabalho e da relação entre ambos, seria de fácil compreensão utilizá-la para definir a Terra como uma grande máquina térmica, e ainda se possível de quantificar qual a eficiência da mesma em transportar este calor para todo o globo. Para isso foi inicialmente realizado a pesquisa de cem cidades do hemisfério norte nas estações de inverno e verão e outras cem cidades do hemisfério sul nas estações de inverno e verão, obtendo suas temperaturas médias máximas para casa estação, acima mencionada, e as latitudes correspondentes. Para o cálculo da eficiência, utiliza-se a equação da eficiência de Carnot, descrita abaixo. Sendo utilizada a temperatura média do Equador como $\mathrm{T}_{2}$, e como $\mathrm{T}_{1}$ as temperaturas médias máximas de cem cidades, do hemisfério sul e hemisfério norte durante o verão e inverno, na década de 2000 a 2010, dando origem a um conjunto de eficiências de Carnot $(\eta)$.

Equação da eficiência de Carnot.

$$
\boldsymbol{\eta}=\mid \underline{\mathrm{T}}_{2}-\frac{\mathrm{T}_{1} \mid}{\left|\mathrm{T}_{1}\right|}
$$

As latitudes são dadas em graus e os minutos e segundos correspondentes foram transformados para o sistema decimal para facilitar os cálculos, dando origem às Tabelas 1 e 2

\section{Resultados}

Alguns processos climáticos produzem entropia, ou seja, onde o ar está sujeito a uma pressão maior num lado do globo que no outro, este desequilíbrio produzirá uma força resultante da região de maior pressão para a região de menor pressão. [6], ou seja, podendo ser relacionado a um motor térmico, para obter sua eficiência é necessário realizar o cálculo da eficiência de Carnot. 
As figuras a seguir representam as latitudes das duzentas cidades dos hemisférios e suas respectivas eficiências de Carnot, obtidas através das temperaturas médias máximas do inverno, sendo o eixo " $x$ " as latitudes e o eixo " $y$ " as eficiências.

As Tabelas 1 e 2 descrevem os resultados das pesquisas e cálculos, também sendo utilizadas para elaboração das figuras 3 e figura 4.

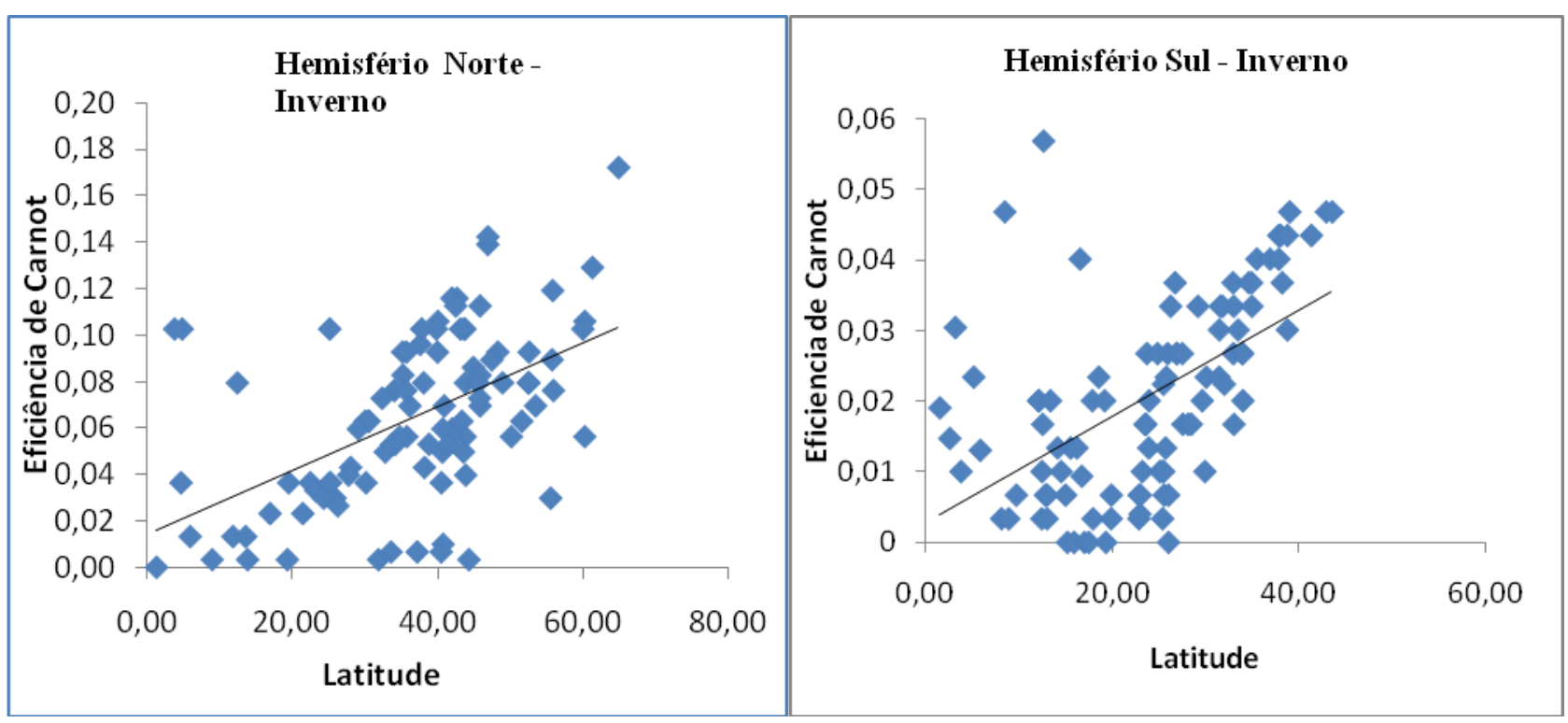

Figura 3: Eficiência de Carnot nos hemisférios Norte e Sul no Inverno.

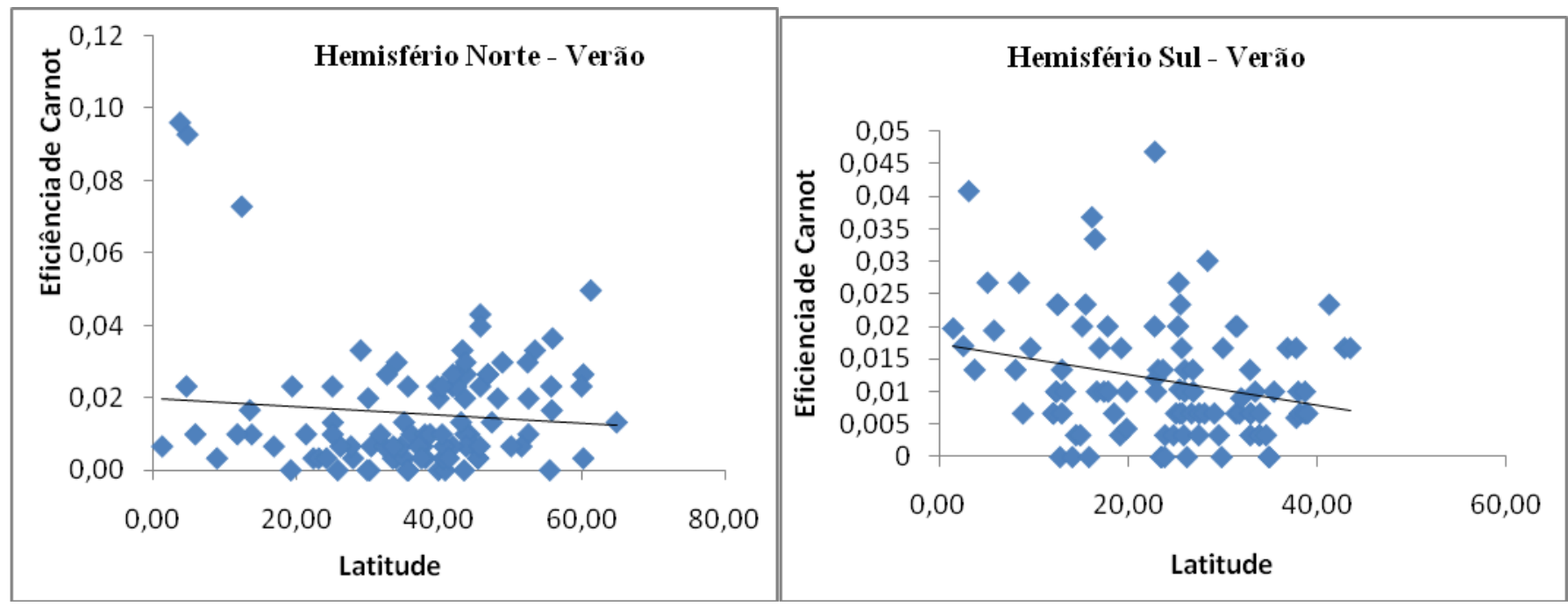

Figura 4: Eficiência de Carnot nos Hemisférios Norte e Sul no Verão.

Tabela 1 - Cem cidades do Hemisfério Sul e suas respectivas temperaturas máximas de verão e inverno, latitude,

\begin{tabular}{|c|c|c|c|c|c|c|}
\hline \multicolumn{2}{|c|}{ país e eficiências de Carnot, em porcentagem. } \\
\hline Cidade & País & $\begin{array}{c}\text { Latitude } \mathbf{n}^{\circ} \\
\text { decimais }\end{array}$ & $\begin{array}{c}\text { TMáx } \\
\text { Verão K }\end{array}$ & $\begin{array}{c}\text { Efic. } \\
\text { Verão }\end{array}$ & $\begin{array}{c}\text { TMáx } \\
\text { Inverno K }\end{array}$ & $\begin{array}{c}\text { Efic. } \\
\text { Inverno }\end{array}$ \\
\hline Bloemfontein & África do Sul & 29,12 & 301 & 0,0067 & 289 & 0,0334 \\
\hline Cidade do Cabo & África do Sul & 33,92 & 298 & 0,0033 & 291 & 0,0268 \\
\hline Durban & África do Sul & 29,88 & 299 & 0,0000 & 296 & 0,0100 \\
\hline East London & África do Sul & 32,98 & 297 & 0,0067 & 294 & 0,0167 \\
\hline
\end{tabular}




\begin{tabular}{|c|c|c|c|c|c|c|}
\hline Joanesburgo & África do Sul & 26,20 & 299 & 0,0000 & 289 & 0,0334 \\
\hline Klerksdorp & África do Sul & 26,87 & 302 & 0,0100 & 291 & 0,0268 \\
\hline Louis Trichardt & África do Sul & 23,15 & 303 & 0,0134 & 296 & 0,0100 \\
\hline Nelspruit & África do Sul & 25,45 & 301 & 0,0067 & 296 & 0,0100 \\
\hline Pietermaritzburg & África do Sul & 29,58 & 298 & 0,0033 & 293 & 0,0201 \\
\hline Polokwane & África do Sul & 23,88 & 300 & 0,0033 & 293 & 0,0201 \\
\hline Porto Elizabeth & África do Sul & 33,95 & 297 & 0,0067 & 293 & 0,0201 \\
\hline Pretória & África do Sul & 25,72 & 301 & 0,0067 & 292 & 0,0234 \\
\hline Rustemburgo & África do Sul & 25,65 & 304 & 0,0167 & 295 & 0,0134 \\
\hline Upington & África do Sul & 28,40 & 308 & 0,0301 & 294 & 0,0167 \\
\hline Vanderbijlpark & África do Sul & 26,68 & 297 & 0,0067 & 288 & 0,0368 \\
\hline Witbank & África do Sul & 25,87 & 298 & 0,0033 & 291 & 0,0268 \\
\hline Benguela & Angola & 12,57 & 292 & 0,0234 & 282 & 0,0569 \\
\hline Huambo & Angola & 12,77 & 299 & 0,0000 & 297 & 0,0067 \\
\hline Kuito & Angola & 12,38 & 296 & 0,0100 & 296 & 0,0100 \\
\hline Lobito & Angola & 12,37 & 302 & 0,0100 & 298 & 0,0033 \\
\hline Luanda & Angola & 8,83 & 301 & 0,0067 & 298 & 0,0033 \\
\hline Lubango & Angola & 14,92 & 298 & 0,0033 & 297 & 0,0067 \\
\hline Lucapa & Angola & 8,42 & 291 & 0,0268 & 285 & 0,0468 \\
\hline Bahía Blanca & Argentina & 38,72 & 301 & 0,0067 & 286 & 0,0435 \\
\hline Buenos Aires & Argentina & 34,58 & 300 & 0,0033 & 288 & 0,0368 \\
\hline Córdoba & Argentina & 31,42 & 301 & 0,0067 & 290 & 0,0301 \\
\hline Mar del Plata & Argentina & 38,00 & 296 & 0,0100 & 286 & 0,0435 \\
\hline Mendoza & Argentina & 32,88 & 303 & 0,0134 & 288 & 0,0368 \\
\hline Neuquén & Argentina & 38,97 & 301 & 0,0067 & 285 & 0,0468 \\
\hline Paraná & Argentina & 31,75 & 301 & 0,0067 & 289 & 0,0334 \\
\hline Rosário & Argentina & 32,95 & 301 & 0,0067 & 289 & 0,0334 \\
\hline Salta & Argentina & 24,78 & 300 & 0,0033 & 291 & 0,0268 \\
\hline San Juan & Argentina & 31,53 & 305 & 0,0201 & 289 & 0,0334 \\
\hline $\begin{array}{l}\text { San Miguel de } \\
\text { Tucumán }\end{array}$ & Argentina & 26,83 & 303 & 0,0134 & 291 & 0,0268 \\
\hline $\begin{array}{l}\text { San Salvador de } \\
\text { Jujuy }\end{array}$ & Argentina & 27,45 & 300 & 0,0033 & 291 & 0,0268 \\
\hline Santa Fé & Argentina & 38,72 & 302 & 0,0100 & 290 & 0,0301 \\
\hline Adelaide & Austrália & 34,92 & 299 & 0,0000 & 289 & 0,0334 \\
\hline Brisbane & Austrália & 27,50 & 301 & 0,0067 & 294 & 0,0167 \\
\hline Cairns & Austrália & 16,95 & 304 & 0,0167 & 299 & 0,0000 \\
\hline Darwin & Austrália & 12,47 & 306 & 0,0234 & 304 & 0,0167 \\
\hline Geelong & Austrália & 38,15 & 297 & 0,0067 & 288 & 0,0368 \\
\hline Gold Coast & Austrália & 28,07 & 301 & 0,0067 & 294 & 0,0167 \\
\hline Hobart & Austrália & 42,88 & 294 & 0,0167 & 285 & 0,0468 \\
\hline Melbourne & Austrália & 37,80 & 297,2 & 0,0060 & 287 & 0,0401 \\
\hline Newcastle & Austrália & 32,92 & 300 & 0,0033 & 291 & 0,0268 \\
\hline Perth & Austrália & 31,95 & 301,7 & 0,0090 & 292,3 & 0,0224 \\
\hline Sidney & Austrália & 33,87 & 298 & 0,0033 & 291 & 0,0268 \\
\hline
\end{tabular}




\begin{tabular}{|c|c|c|c|c|c|c|}
\hline Townsville & Austrália & 19,25 & 304 & 0,0167 & 299 & 0,0000 \\
\hline Cochabamba & Bolívia & 17,42 & 302 & 0,0100 & 299 & 0,0000 \\
\hline $\mathrm{La} \mathrm{Paz}$ & Bolívia & 16,48 & 289 & 0,0334 & 287 & 0,0401 \\
\hline $\begin{array}{c}\text { Santa Cruz de la } \\
\text { Sierra }\end{array}$ & Bolívia & 17,80 & 305 & 0,0201 & 293 & 0,0201 \\
\hline Belém & Brasil & 1,45 & 304,9 & 0,0197 & 304,7 & 0,0191 \\
\hline Belo Horizonte & Brasil & 19,82 & 300,3 & 0,0043 & 298 & 0,0033 \\
\hline Brasília & Brasil & 15,83 & 299 & 0,0000 & 299 & 0,0000 \\
\hline Campinas & Brasil & 22,90 & 302,6 & 0,0120 & 297,8 & 0,0040 \\
\hline Curitiba & Brasil & 25,42 & 302,1 & 0,0104 & 292,3 & 0,0224 \\
\hline Duque de Caxias & Brasil & 22,78 & 305 & 0,0201 & 300 & 0,0033 \\
\hline Fortaleza & Brasil & 3,72 & 303 & 0,0134 & 302 & 0,0100 \\
\hline Goiânia & Brasil & 16,67 & 302 & 0,0100 & 301,8 & 0,0094 \\
\hline Guarulhos & Brasil & 23,45 & 299 & 0,0000 & 294 & 0,0167 \\
\hline Maceió & Brasil & 9,65 & 304 & 0,0167 & 301 & 0,0067 \\
\hline Manaus & Brasil & 3,10 & 311,2 & 0,0408 & 308,1 & 0,0304 \\
\hline Natal & Brasil & 5,78 & 304,8 & 0,0194 & 302,9 & 0,0130 \\
\hline Porto Alegre & Brasil & 30,02 & 304 & 0,0167 & 292 & 0,0234 \\
\hline Recife & Brasil & 8,05 & 303 & 0,0134 & 300 & 0,0033 \\
\hline Rio de Janeiro & Brasil & 22,93 & 302 & 0,0100 & 297 & 0,0067 \\
\hline Salvador & Brasil & 12,97 & 303 & 0,0134 & 301 & 0,0067 \\
\hline São Gonçalo & Brasil & 22,82 & 313 & 0,0468 & 297 & 0,0067 \\
\hline São Luís & Brasil & 2,52 & 304,1 & 0,0171 & 303,4 & 0,0147 \\
\hline São Paulo & Brasil & 23,53 & 299 & 0,0000 & 294 & 0,0167 \\
\hline Teresina & Brasil & 5,08 & 307 & 0,0268 & 306 & 0,0234 \\
\hline Antofagasta & Chile & 23,65 & 295 & 0,0134 & 291 & 0,0268 \\
\hline Arica & Chile & 18,48 & 297 & 0,0067 & 292 & 0,0234 \\
\hline Santiago & Chile & 33,43 & 302 & 0,0100 & 290 & 0,0301 \\
\hline Talca & Chile & 35,43 & 302 & 0,0100 & 287 & 0,0401 \\
\hline Beira & Moçambique & 19,83 & 302 & 0,0100 & 297 & 0,0067 \\
\hline Chimoio & Moçambique & 19,12 & 298 & 0,0033 & 293 & 0,0201 \\
\hline Gurué & Moçambique & 15,47 & 292 & 0,0234 & 295 & 0,0134 \\
\hline Lichinga & Moçambique & 13,30 & 296 & 0,0100 & 293 & 0,0201 \\
\hline Maputo & Moçambique & 25,97 & 302 & 0,0100 & 297 & 0,0067 \\
\hline Matola & Moçambique & 25,97 & 303 & 0,0134 & 299 & 0,0000 \\
\hline Maxixe & Moçambique & 23,85 & 299 & 0,0000 & 295 & 0,0134 \\
\hline Nacala Porto & Moçambique & 14,45 & 298 & 0,0033 & 296 & 0,0100 \\
\hline Nampula & Moçambique & 15,12 & 305 & 0,0201 & 299 & 0,0000 \\
\hline Pemba & Moçambique & 12,95 & 301 & 0,0067 & 300 & 0,0033 \\
\hline Quelimane & Moçambique & 17,87 & 302 & 0,0100 & 298 & 0,0033 \\
\hline Tete & Moçambique & 16,15 & 310 & 0,0368 & 303 & 0,0134 \\
\hline Xai-Xai & Moçambique & 25,05 & 301 & 0,0067 & 296 & 0,0100 \\
\hline Auckland & Nova Zelândia & 36,85 & 294 & 0,0167 & 287 & 0,0401 \\
\hline Christchurch & Nova Zelândia & 43,52 & 294 & 0,0167 & 285 & 0,0468 \\
\hline Hamilton & Nova Zelândia & 37,78 & 294 & 0,0167 & 286 & 0,0435 \\
\hline
\end{tabular}




\begin{tabular}{|c|c|c|c|c|c|c|} 
Wellington & Nova Zelândia & 41,28 & 292 & 0,0234 & 286 & 0,0435 \\
\hline Assunção & Paraguai & 25,27 & 305 & 0,0201 & 296 & 0,0100 \\
\hline Ciudad del Este & Paraguai & 25,50 & 306 & 0,0234 & 297 & 0,0067 \\
\hline San Lorenzo & Paraguai & 25,33 & 307 & 0,0268 & 298 & 0,0033 \\
\hline Callao & Peru & 12,07 & 297 & 0,0067 & 293 & 0,0201 \\
\hline Ica & Peru & 14,07 & 299 & 0,0000 & 295 & 0,0134 \\
\hline Lima & Peru & 12,05 & 297 & 0,0067 & 293 & 0,0201 \\
\hline Montevidéu & Uruguai & 34,88 & 299 & 0,0000 & 288 & 0,0368 \\
\hline Salto & Uruguai & 31,38 & 305 & 0,0201 & 292 & 0,0234 \\
\hline
\end{tabular}

Tabela 2 - cem cidades do Hemisfério Norte e suas respectivas temperaturas máximas de verão e inverno, latitude, país e eficiências de Carnot, em porcentagem.

\begin{tabular}{|c|c|c|c|c|c|c|}
\hline Cidades & Países & $\begin{array}{l}\text { Latitude } \mathrm{n}^{\circ} \\
\text { decimais }\end{array}$ & $\begin{array}{l}\text { T.Max. } \\
\text { Verão K }\end{array}$ & $\begin{array}{l}\text { Efic. } \\
\text { Verão }\end{array}$ & $\begin{array}{l}\text { T. Max. } \\
\text { Inverno K }\end{array}$ & $\begin{array}{l}\text { Efic. } \\
\text { Inverno }\end{array}$ \\
\hline Albany & $\begin{array}{l}\text { América do } \\
\text { Norte }\end{array}$ & 42,58 & 294 & 0,0265 & 267 & 0,1159 \\
\hline Albuquerque & $\begin{array}{c}\text { América do } \\
\text { Norte }\end{array}$ & 35,08 & 298 & 0,0132 & 274 & 0,0927 \\
\hline Anchorage & $\begin{array}{l}\text { América do } \\
\text { Norte }\end{array}$ & 61,22 & 287 & 0,0497 & 263 & 0,1291 \\
\hline Asheville & $\begin{array}{l}\text { América do } \\
\text { Norte }\end{array}$ & 35,62 & 295 & 0,0232 & 274 & 0,0927 \\
\hline Austin & $\begin{array}{l}\text { América do } \\
\text { Norte }\end{array}$ & 30,27 & 302 & 0,0000 & 283 & 0,0629 \\
\hline Baton Rouge & $\begin{array}{l}\text { América do } \\
\text { Norte }\end{array}$ & 30,48 & 300 & 0,0066 & 283 & 0,0629 \\
\hline Billings & $\begin{array}{c}\text { América do } \\
\text { Norte }\end{array}$ & 45,75 & 295 & 0,0232 & 268 & 0,1126 \\
\hline Birmingham & $\begin{array}{l}\text { América do } \\
\text { Norte }\end{array}$ & 52,47 & 299 & 0,0099 & 278 & 0,0795 \\
\hline Boise & $\begin{array}{l}\text { América do } \\
\text { Norte }\end{array}$ & 43,60 & 296 & 0,0199 & 271 & 0,1026 \\
\hline Bismark & $\begin{array}{l}\text { América do } \\
\text { Norte }\end{array}$ & 46,80 & 294 & 0,0265 & 260 & 0,1391 \\
\hline Chicago & $\begin{array}{l}\text { América do } \\
\text { Norte }\end{array}$ & 41,87 & 295 & 0,0232 & 267 & 0,1159 \\
\hline Columbia & $\begin{array}{l}\text { América do } \\
\text { Norte }\end{array}$ & 33,95 & 301 & 0,0033 & 279 & 0,0762 \\
\hline Columbus & $\begin{array}{l}\text { América do } \\
\text { Norte }\end{array}$ & 39,95 & 296 & 0,0199 & 270 & 0,1060 \\
\hline Kingston & $\begin{array}{l}\text { América do } \\
\text { Norte }\end{array}$ & 44,22 & 305 & 0,0099 & 303 & 0,0033 \\
\hline San Juan & $\begin{array}{c}\text { América do } \\
\text { Norte }\end{array}$ & 33,50 & 303 & 0,0033 & 300 & 0,0066 \\
\hline Denver & $\begin{array}{c}\text { América do } \\
\text { Norte }\end{array}$ & 39,73 & 295 & 0,0232 & 271 & 0,1026 \\
\hline Honolulu & América do & 21,35 & 299 & 0,0099 & 295 & 0,0232 \\
\hline
\end{tabular}




\begin{tabular}{|c|c|c|c|c|c|c|}
\hline & Norte & & & & & \\
\hline Tampa & $\begin{array}{l}\text { América do } \\
\text { Norte }\end{array}$ & 27,93 & 301 & 0,0033 & 289 & 0,0430 \\
\hline Vero Beach & $\begin{array}{l}\text { América do } \\
\text { Norte }\end{array}$ & 27,65 & 300 & 0,0066 & 290 & 0,0397 \\
\hline Wichita & $\begin{array}{c}\text { América do } \\
\text { Norte }\end{array}$ & 37,72 & 300 & 0,0066 & 271 & 0,1026 \\
\hline Toronto & $\begin{array}{l}\text { América do } \\
\text { Norte }\end{array}$ & 43,65 & 299 & 0,0099 & 271 & 0,1026 \\
\hline Vancouver & $\begin{array}{l}\text { América do } \\
\text { Norte }\end{array}$ & 43,73 & 294 & 0,0265 & 278 & 0,0795 \\
\hline San Diego & $\begin{array}{l}\text { América do } \\
\text { Norte }\end{array}$ & 32,70 & 294 & 0,0265 & 287 & 0,0497 \\
\hline Memphis & $\begin{array}{l}\text { América do } \\
\text { Norte }\end{array}$ & 35,13 & 301 & 0,0033 & 277 & 0,0828 \\
\hline Los Angeles & $\begin{array}{l}\text { América do } \\
\text { Norte }\end{array}$ & 34,05 & 293 & 0,0298 & 286 & 0,0530 \\
\hline Fargo & $\begin{array}{l}\text { América do } \\
\text { Norte }\end{array}$ & 46,83 & 294 & 0,0265 & 259 & 0,1424 \\
\hline Fairbanks & $\begin{array}{l}\text { América do } \\
\text { Norte }\end{array}$ & 64,83 & 298 & 0,0132 & 250 & 0,1722 \\
\hline Houston & $\begin{array}{c}\text { América do } \\
\text { Norte }\end{array}$ & 29,93 & 302 & 0,0000 & 283 & 0,0629 \\
\hline Miami & $\begin{array}{l}\text { América do } \\
\text { Norte }\end{array}$ & 25,78 & 302 & 0,0000 & 293 & 0,0298 \\
\hline New Orleans & $\begin{array}{l}\text { América do } \\
\text { Norte }\end{array}$ & 29,00 & 292 & 0,0331 & 284 & 0,0596 \\
\hline Las Vegas & $\begin{array}{c}\text { América do } \\
\text { Norte }\end{array}$ & 36,10 & 305 & 0,0099 & 281 & 0,0695 \\
\hline Jackson & $\begin{array}{l}\text { América do } \\
\text { Norte }\end{array}$ & 32,28 & 300 & 0,0066 & 280 & 0,0728 \\
\hline Dublin & $\begin{array}{l}\text { América do } \\
\text { Norte }\end{array}$ & 53,40 & 292 & 0,0331 & 281 & 0,0695 \\
\hline Glasgow & $\begin{array}{l}\text { América do } \\
\text { Norte }\end{array}$ & 55,85 & 291 & 0,0364 & 279 & 0,0762 \\
\hline Belgrade & $\begin{array}{l}\text { América do } \\
\text { Norte }\end{array}$ & 44,82 & 300 & 0,0066 & 276 & 0,0861 \\
\hline Detroit & $\begin{array}{c}\text { América do } \\
\text { Norte }\end{array}$ & 42,40 & 295 & 0,0232 & 268 & 0,1126 \\
\hline Saporo & Japão & 43,05 & 298 & 0,0132 & 271 & 0,1026 \\
\hline Tokyo & Japão & 35,67 & 302 & 0,0000 & 285 & 0,0563 \\
\hline Takayama & Japão & 35,53 & 302 & 0,0000 & 279 & 0,0762 \\
\hline Osaka & Japão & 34,68 & 304 & 0,0066 & 285 & 0,0563 \\
\hline Fukuoka & Japão & 33,58 & 304 & 0,0066 & 286 & 0,0530 \\
\hline Naha & Japão & 26,17 & 304 & 0,0066 & 294 & 0,0265 \\
\hline Pequim & China & 39,88 & 302 & 0,0000 & 274 & 0,0927 \\
\hline Hong Kong & China & 22,38 & 301 & 0,0033 & 291 & 0,0364 \\
\hline Taipei & China & 25,10 & 306 & 0,0132 & 291 & 0,0364 \\
\hline
\end{tabular}




\begin{tabular}{|c|c|c|c|c|c|c|}
\hline Tainan & Taiwan & 23,13 & 303 & 0,0033 & 292 & 0,0331 \\
\hline Taichung & Taiwan & 24,22 & 303 & 0,0033 & 293 & 0,0298 \\
\hline Taipe & Taiwan & 25,08 & 305 & 0,0099 & 291 & 0,0364 \\
\hline Paris & França & 48,85 & 293 & 0,0298 & 278 & 0,0795 \\
\hline Ajaccio & França & 41,90 & 294 & 0,0265 & 284 & 0,0596 \\
\hline $\begin{array}{l}\text { Bourg-Saint- } \\
\text { Maurice }\end{array}$ & França & 45,74 & 289 & 0,0430 & 277 & 0,0828 \\
\hline Carcassonne & França & 43,25 & 292 & 0,0331 & 283 & 0,0629 \\
\hline Lyon & França & 45,75 & 290 & 0,0397 & 281 & 0,0695 \\
\hline Nice & França & 43,68 & 293 & 0,0298 & 285 & 0,0563 \\
\hline Acapulco & México & 16,85 & 304 & 0,0066 & 295 & 0,0232 \\
\hline $\begin{array}{l}\text { Cidade do } \\
\text { México }\end{array}$ & México & 19,42 & 295 & 0,0232 & 291 & 0,0364 \\
\hline Amsterdã & Holanda & 52,38 & 293 & 0,0298 & 278 & 0,0795 \\
\hline Atenas & Grecia & 37,98 & 305 & 0,0099 & 278 & 0,0795 \\
\hline Bang Kok & Tailândia & 13,75 & 305 & 0,0099 & 303 & 0,0033 \\
\hline Berlim & Alemanha & 52,50 & 296 & 0,0199 & 274 & 0,0927 \\
\hline Nassau & Alemanha & 25,05 & 295 & 0,0232 & 271 & 0,1026 \\
\hline Nápoles & Itália & 40,82 & 302 & 0,0000 & 281 & 0,0695 \\
\hline Palermo & Itália & 38,10 & 301 & 0,0033 & 289 & 0,0430 \\
\hline Milão & Itália & 45,45 & 301 & 0,0033 & 278 & 0,0795 \\
\hline Florença & Itália & 43,77 & 304 & 0,0066 & 290 & 0,0397 \\
\hline Roma & Itália & 41,90 & 304 & 0,0066 & 285 & 0,0563 \\
\hline Arezzo & Itália & 43,47 & 302 & 0,0000 & 287 & 0,0497 \\
\hline Alghero & Itália & 40,55 & 301 & 0,0033 & 287 & 0,0497 \\
\hline Verona & Itália & 45,43 & 301 & 0,0033 & 278 & 0,0795 \\
\hline Positano & Itália & 40,62 & 301 & 0,0033 & 284 & 0,0596 \\
\hline Bombay & India & 19,22 & 302 & 0,0000 & 301 & 0,0033 \\
\hline Calcuta & India & 40,67 & 304 & 0,0066 & 299 & 0,0099 \\
\hline Bissau & India & 11,73 & 299 & 0,0099 & 298 & 0,0132 \\
\hline Cairo & Egito & 30,05 & 308 & 0,0199 & 291 & 0,0364 \\
\hline Copenhagem & Dinamarca & 55,67 & 295 & 0,0232 & 275 & 0,0894 \\
\hline Hamilton & Reino Unido & 55,47 & 302 & 0,0000 & 293 & 0,0298 \\
\hline Londres & Reino Unido & 51,50 & 304 & 0,0066 & 283 & 0,0629 \\
\hline Helsinki & Finlândia & 60,17 & 294 & 0,0265 & 270 & 0,1060 \\
\hline Istanbul & Turquia & 60,17 & 303 & 0,0033 & 285 & 0,0563 \\
\hline Jerusalem & Israel & 31,77 & 305 & 0,0099 & 303 & 0,0033 \\
\hline Lagos & Nigéria & 37,10 & 304 & 0,0066 & 300 & 0,0066 \\
\hline Montreal & Nigéria & 45,68 & 300 & 0,0066 & 280 & 0,0728 \\
\hline Niamey & Nigéria & 13,48 & 307 & 0,0166 & 306 & 0,0132 \\
\hline Abuja & Nigéria & 8,88 & 303 & 0,0033 & 303 & 0,0033 \\
\hline Lisboa & Portugal & 38,72 & 299 & 0,0099 & 286 & 0,0530 \\
\hline Barcelona & Espanha & 41,37 & 301 & 0,0033 & 286 & 0,0530 \\
\hline Madrid & Espanha & 40,42 & 295 & 0,0232 & 291 & 0,0364 \\
\hline
\end{tabular}




\begin{tabular}{|c|c|c|c|c|c|c|} 
Moscow & Russia & 55,75 & 297 & 0,0166 & 266 & 0,1192 \\
\hline Oslo & Noruega & 59,90 & 295 & 0,0232 & 271 & 0,1026 \\
\hline Praga & $\begin{array}{c}\text { Republica } \\
\text { Theca }\end{array}$ & 50,06 & 304 & 0,0066 & 285 & 0,0563 \\
\hline Seoul & Coreia do Sul & 37,52 & 301 & 0,0033 & 273 & 0,0960 \\
\hline Viena & Austria & 48,20 & 296 & 0,0199 & 274 & 0,0927 \\
\hline Zurich & Suiça & 47,37 & 298 & 0,0132 & 275 & 0,0894 \\
\hline Juba & Sudão & 4,75 & 274 & 0,0927 & 271 & 0,1026 \\
\hline Yaounde & Camarões & 3,70 & 273 & 0,0960 & 271 & 0,1026 \\
\hline Uagadugu & África & 12,35 & 280 & 0,0728 & 278 & 0,0795 \\
\hline Paramaribo & Suriname & 5,85 & 299 & 0,0099 & 298 & 0,0132 \\
\hline Bogota & Colombia & 4,60 & 295 & 0,0232 & 291 & 0,0364 \\
\hline Singapura & Malásia & 1,22 & 304 & 0,0066 & 302 & 0,0000 \\
\hline Hanoi & Vietnam & 40,40 & 305 & 0,0099 & 300 & 0,0066 \\
\hline
\end{tabular}

\section{Discussão}

Partindo da premissa que o globo é uma grande máquina térmica, observando a figura 3, nota-se que na faixa do trópico de câncer na região do hemisfério norte e o trópico de capricórnio no hemisfério sul no inverno não há uma grande inclinação da linha exponencial, isso ocorre devido a quantidade de radiação solar que incide nesta região sendo o suficiente para aquecer o local sem haver uma grande necessidade de transferência de calor, porém a medida que aumenta-se a latitude no globo, a linha exponencial tende a ser mais inclinada, isso devido a uma maior transferência de calor que é realizada pelos ventos amenizando o aquecimento entre os trópicos e levando este calor para os pólos.

Com relação a figura 3, nota-se que a linha exponencial possui uma leve inclinação a uma menor eficiência partindo da linha do equador para os trópicos o que é inverso aos gráficos da figura 3, porém isso pode ter se dado por eventos climáticos ocorridos nesta época que venha a aquecer às altas latitudes, ou talvez derivados por ilhas de calor, levando a uma menor necessidade de transferência de calor, mas se levarmos em conta apenas os pontos notamos que esta reta estaria não inclinada, mas sim horizontalmente direcionada.

\section{Conclusão}

Como se pode notar nas Figuras 1 e 2, quanto maior a latitude maior a eficiência. Isso acontece devido à maior transferência de radiação solar que ocorre da linha do Equador para os pólos. Sendo assim, verão do hemisfério norte a Terra estando inclinada de forma que os raios solares incidam com maior concentração nas proximidades do trópico de câncer, 
dando origem ao verão do hemisfério norte, o contrário ocorre em relação ao inverno desta mesma região onde os raios solares incidem com maior concentração nas proximidades do trópico de capricórnio, dando origem ao verão do hemisfério sul.

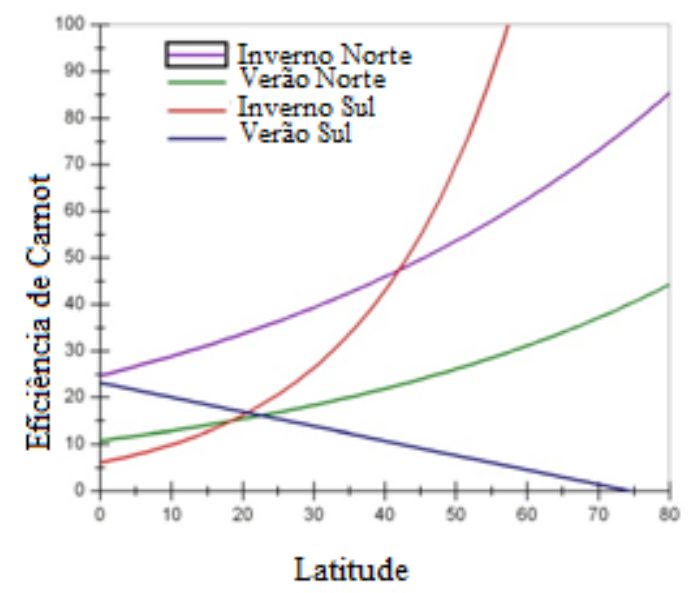

Figura 5: Comparação entre as curvas de eficiência dos hemisférios Norte e sul nas estações de verão e inverno.

Imaginando que a Terra seja uma grande máquina térmica, uma maior concentração de raios solares atinge a linha do equador até aos trópicos, assim nesta região a eficiência na transferência de calor será menor que em comparação às latitudes superiores aos trópicos, que iria necessitar de uma eficiência de transferência de calor maior para levar o calor recebido até os pólos. Nota-se que na Figura 3 a linha está inclinada para uma menor eficiência com o aumento da latitude, isso pode ter se dado por eventos climáticos ocorridos nesta época que venha a aquecer às altas latitudes, ou talvez derivados por ilhas de calor. Mas se levarmos em conta apenas os pontos, notamos que esta linha estaria não inclinada, mas sim horizontalmente direcionada.

Em relação às curvas, se pode observar que houve uma maior deflexão no inverno do hemisfério sul do que no hemisfério norte, na mesma estação, provavelmente devido a uma possível mudança climática ou ilhas de calor que ocorrem com maior intensidade nas regiões norte do que no sul, talvez pelo fato de localizarem-se nestas cidades as indústrias e pelo fato de estas estarem mais desenvolvidas, pois tendo essa fonte de calor, a transferência de calor diminui e com isso a eficiência de Carnot também. Por fim pode-se concluir que a Terra é uma enorme máquina térmica e que suas mudanças climáticas estão diretamente relacionadas à transferência de calor. 


\section{Referências Bibliográficas}

[1] FIGUEIREDO, A.M. Termodinâmica Aplicada. 2008.

[2] MENDONÇA, F. DANNI-OLIVEIRA, I. M. Climatologia. Noções básicas e climas do Brasil. São Paulo: Oficina de Textos, 2007.

[3] FERREIRA, W.P.M. Radiação Solar em Sete Lagoas, MG. Embrapa, 2006.

[4] P.M.C. de Oliveira; K. Dechoum. Facilitando a compreensão da segunda lei da termodinâmica. Instituto de Física, Universidade Federal Fluminense, 2003.

[5] Levenspiel, Octave. Termodinâmica Amistosa para Engenheiros; Editora Edgard Blücher LTDA.

[6] UFPR, Física: Força de gradiente de pressão. Disponível em:

< http://fisica.ufpr.br/grimm/aposmeteo/cap7/cap7-2.html > . Acesso em 08/05/2013

[7] GeoMundo: O Efeito Coriolis no planeta Terra. Disponível em:

<http://www.geomundo.com.br/meio-ambiente-40137.htm >. Acesso em 03/05/2013. 